\title{
Changes in macular pigment optical density and serum concentrations of lutein and zeaxanthin in response to weight loss
}

\author{
Mark L. Kirby ${ }^{1 *}$, Stephen Beatty ${ }^{1}$, Jim Stack $^{1}$, Michael Harrison $^{2}$, Isabelle Greene ${ }^{3}$, Sean McBrinn ${ }^{4}$, \\ Paula Carroll ${ }^{2}$ and John M. Nolan ${ }^{1}$ \\ ${ }^{1}$ Macular Pigment Research Group, Department of Chemical and Life Sciences, Waterford Institute of Technology, Waterford, \\ Republic of Ireland \\ ${ }^{2}$ Department of Health, Sport and Exercise Science, Waterford Institute of Technology, Waterford, Republic of Ireland \\ ${ }^{3}$ Department of Dietetics, Waterford Regional Hospital, Waterford, Republic of Ireland \\ ${ }^{4}$ Student Medical Centre, Waterford Institute of Technology, Waterford, Republic of Ireland
}

(Received 5 January 2010 - Revised 18 October 2010 - Accepted 19 October 2010 - First published online 9 December 2010)

\begin{abstract}
The objective of the present study was to investigate whether weight loss is associated with changes in serum concentrations of lutein (L) and zeaxanthin (Z), and/or macular pigment optical density (MPOD). We recruited 104 overweight subjects into this randomised controlled weight loss study. For the intervention group (I group), weight was assessed weekly and body composition, including BMI ( $\mathrm{kg} / \mathrm{m}^{2}$ ) and body fat ( $\mathrm{kg}$ and percentage), was assessed at baseline, 6 and 12 months. Weight loss was encouraged using dietary and exercise programmes. MPOD was measured by heterochromatic flicker photometry and serum concentrations of L and Z by HPLC (at baseline, 1, 3, 6 and 12 months). The control (C) group was assessed at baseline and 12 months. Repeated-measures ANOVA (RMA) demonstrated significant weight loss in the I group over the study period $(P=0 \cdot 000)$. There was no significant weight change in the $\mathrm{C}$ group $(P=0 \cdot 993)$. RMA of dietary L and Z, serum L and Z, and MPOD demonstrated no significant time or time $\times$ group interaction effect in any of these parameters $(P>0.05$ for all), with the exception of a significant decrease in the dietary intake of $Z$ seen in both groups, over the study period $(P<0.05)$. There was a positive and significant relationship between body fat loss $(\mathrm{kg})$ and increase in serum concentrations of $\mathrm{L}$ in the I group $(r$ 0.521; $P=0.006)$. Our finding that a reduction in body composition (e.g. fat mass) is related to increases in serum concentrations of $\mathrm{L}$ is consistent with the hypothesis that body fat acts as a reservoir for this carotenoid, and that weight loss can positively influence circulating carotenoid levels.
\end{abstract}

Key words: Weight loss: Obesity: Serum concentrations of lutein/zeaxanthin: Macular pigment

Carotenoids are a group of naturally occurring plant pigments, which are entirely of dietary origin and are found in coloured fruits and green leafy vegetables ${ }^{(1)}$. In the human body, carotenoids have been identified in various tissues such as the liver, kidney, spleen, adipose tissue and the retina ${ }^{(2)}$. At the centre of the retina, a region known as the macula, carotenoids such as lutein (L), zeaxanthin ( $\mathrm{Z}$ ) and meso-Z (an isomer of $\mathrm{L}$ generated at the retina) are referred to as macular pigment (MP). MP is the most conspicuous accumulation of carotenoids in the human body ${ }^{(3,4)}$.

Age-related macular degeneration (AMD) is the leading cause of blindness in the Western world ${ }^{(5)}$. While the precise aetiopathogenesis of AMD is unclear, it is believed to be caused by a combination of cumulative and chronic insult from reactive oxygen species, which are mainly generated from oxygen metabolism and short-wavelength (blue) light exposure, and chronic inflammation ${ }^{(6)}$. MP is a short-wavelength (blue) light filter, a powerful antioxidant, and more recently, has been suggested to have anti-inflammatory properties ${ }^{(7)}$. MP is therefore believed to protect against AMD. This role of the macular carotenoids is referred to as the 'protective hypothesis of MP' and has been reported on extensively in the literature ${ }^{(8)}$.

Another proposed role of the macular carotenoids rests on their optical (rather than antioxidant) properties and their contribution to visual performance ${ }^{(9)}$. These 'optical' hypotheses relate to at least one of the following properties: enhancement of visual acuity by reducing chromatic aberration; reduction of visual discomfort by

Abbreviations: AMD, age-related macular degeneration; C, control; I, intervention; L, lutein; MP, macular pigment; MPOD, macular pigment optical density; Z, zeaxanthin.

*Corresponding author: Dr M. L. Kirby, email lexmark_16@hotmail.com 
attenuation of glare and dazzle; enhancement of detail by the absorption of 'blue haze'; enhancement of visual contrast. In brief, therefore, it appears that $\mathrm{L}, \mathrm{Z}$ and meso-Z play important functional roles at the macula, such as those described above.

In 1997, the WHO announced that global obesity was at epidemic levels ${ }^{(10)}$. Since then, the prevalence of obesity has continued to increase in both adult and child populations $^{(11)}$. Obesity is simply defined as an excess of body fat. Body fat is of particular interest to the present investigation because it is a major storage organ for carotenoids $^{(2,12)}$. Interestingly, an inverse relationship between macular pigment optical density (MPOD) and various measures of obesity has been demonstrated in recently published studies ${ }^{(13,14)}$. Of note, some studies have demonstrated an increased risk of AMD in association with obesity ${ }^{(15)}$. Some investigators have suggested that adipose tissue acts as a sink/reservoir for $\mathrm{L}$ and $\mathrm{Z}^{(13,14,16)}$. Therefore, variation in a person's body fat may influence carotenoid concentrations in the serum and host tissues such as the retina. In addition, obesity has been shown to result in an unfavourable high ratio of circulating LDL:HDL ${ }^{(17)}$. Given that HDL-cholesterol is known to be the most efficient transporter of $\mathrm{L}$ and $\mathrm{Z}$ to the retina, a high LDL:HDL ratio in obese individuals may therefore impair transport and delivery of the macular carotenoids to this host tissue ${ }^{(18)}$. Finally, it is also possible that a relative lack of MPOD seen in obese subjects may simply reflect a poor diet among these individuals, as it has been demonstrated that obesity is associated with reduced dietary intake of the macular carotenoids; however, it should be noted that in the study performed by Nolan et $a l .^{(14,19)}$, the inverse relationship between body fat and MPOD remained even after controlling for dietary intake of the macular carotenoids.

It is important to note that the above-discussed studies were cross-sectional in design and, therefore, were not suitable to investigate whether weight loss is associated with changes in serum carotenoid concentrations and/ or MPOD in overweight and obese individuals. We hypothesise, therefore, that weight loss in overweight and obese individuals may alter serum macular carotenoid concentrations and consequentially MPOD. We present data from a 12-month, randomised controlled weight loss trial (Adipose Carotenoid Trial in Overweight Normals; ACTION), designed to measure related changes, if any, in MPOD (at $0.25^{\circ}, 0.5^{\circ}$, $1.0^{\circ}$ and $1.75^{\circ}$ retinal eccentricity) and serum concentrations of $\mathrm{L}$ and $\mathrm{Z}$, in overweight and obese individuals.

\section{Methods}

\section{Subjects}

A total of 104 subjects were recruited to participate in this randomised controlled weight loss trial (Fig. 1). The present study was conducted according to the guidelines

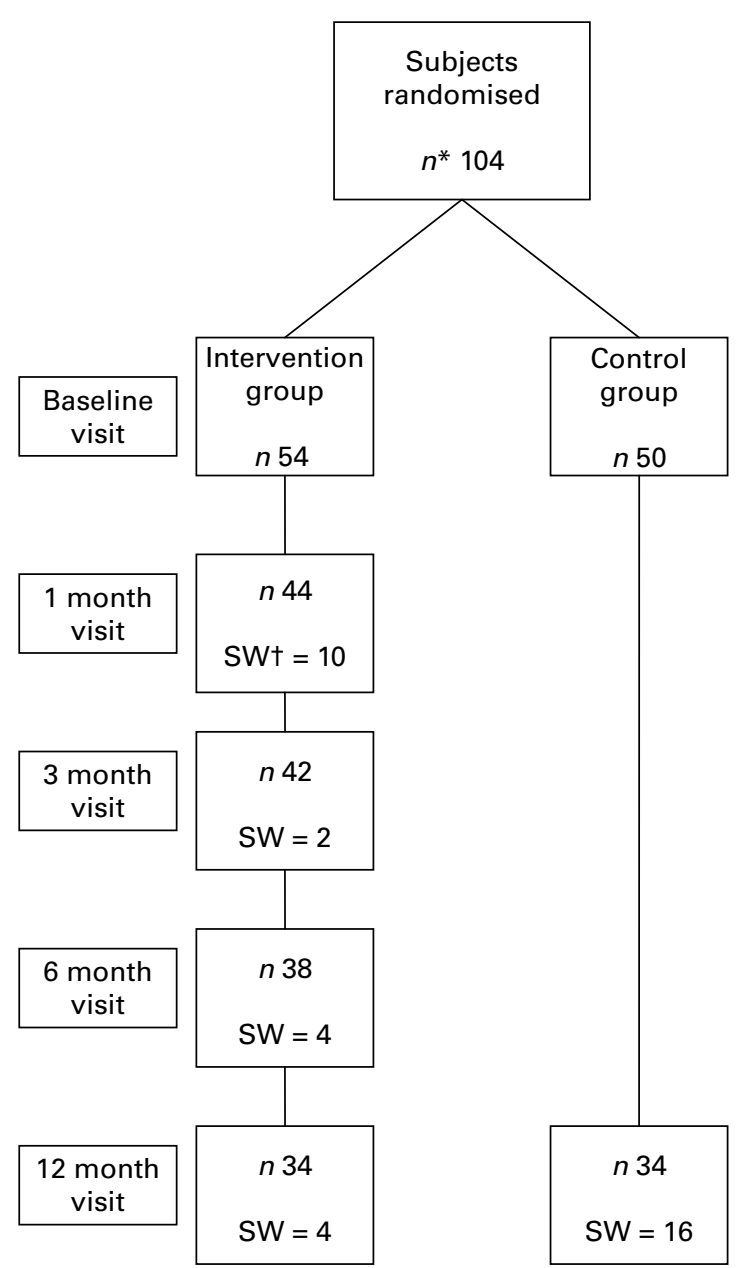

Fig. 1. Consort diagram of participant flow over the 12-month study period. * Number of subjects who fully completed the study visit. †Number of subjects who self-withdrew. SW, self-withdrew.

laid down in the Declaration of Helsinki, and all procedures involving human subjects were approved by the local research ethics committees at both Waterford Regional Hospital and Waterford Institute of Technology. Following a detailed explanation of all aspects of the study and its design, written informed consent was obtained from each subject.

Assuming a difference of $0 \cdot 1$ MPOD units is statistically significant and that the test-retest correlation of MP is $0 \cdot 8$, the following power calculations were performed. For a power of $0 \cdot 80$, the study required twenty-two intervention subjects and twenty-two control subjects. For a power of 0.90 , the study required thirty subjects in each group. Given that the study has a 12-month time gap, dropouts were likely so the statistical advice was to recruit at least forty-five subjects in each group.

Following their baseline visit, all subjects were randomly assigned to either the intervention (I) or the control (C) group of the study (Fig. 1). Randomisation was performed by an independent statistician based at Waterford Institute of Technology (J. S.). Parameters assessed at each study visit, and for each group (i.e. I and C), are outlined in Table 1. 
Table 1. Data collected at each study visit for the intervention and control groups

\begin{tabular}{|c|c|c|}
\hline Visit & Intervention group & Control group \\
\hline Baseline & $\begin{array}{l}\text { MPOD*; serum L and Z; serum } \\
\text { lipoprotein profile; ht; wt; BMI; \% } \\
\text { body fat†; FFQł; fundus photograph }\end{array}$ & $\begin{array}{l}\text { MPOD; serum L and Z; serum } \\
\text { lipoprotein profile; ht; wt; BMI; FFQ; } \\
\% \text { body fat; fundus photograph }\end{array}$ \\
\hline $\begin{array}{l}\text { Baseline dietary } \\
\text { intervention }\end{array}$ & Dietitian consultation§ & $\mathrm{n} / \mathrm{a}$ \\
\hline 1 month & $\begin{array}{l}\text { MPOD; serum L and Z; serum } \\
\quad \text { lipoprotein profile; ht; wt; BMI }\end{array}$ & $\mathrm{n} / \mathrm{a}$ \\
\hline 3 months & $\begin{array}{l}\text { MPOD; serum L and Z; serum } \\
\text { lipoprotein profile; ht; wt; BMI; FFQ }\end{array}$ & $\mathrm{n} / \mathrm{a}$ \\
\hline 6 months & $\begin{array}{l}\text { MPOD; serum L and Z; serum } \\
\text { lipoprotein profile; ht; wt; BMI; FFQ; } \\
\% \text { body fat }\end{array}$ & $\mathrm{n} / \mathrm{a}$ \\
\hline 12 months & $\begin{array}{l}\text { MPOD; serum L and Z; serum } \\
\text { lipoprotein profile; ht, wt; BMI; FFQ; } \\
\% \text { body fat }\end{array}$ & $\begin{array}{l}\text { MPOD; serum L and Z; serum } \\
\text { lipoprotein profile; ht; wt; BMI; FFQ; } \\
\text { \% body fat }\end{array}$ \\
\hline
\end{tabular}

\section{Inclusion and exclusion criteria}

Inclusion criteria were as follows: $\mathrm{BMI} \geq 28 \mathrm{~kg} / \mathrm{m}^{2}$; age $\geq 18$ years; no known family history of AMD; no ocular pathology. Exclusion criteria were as follows: pregnancy; planning pregnancy; currently participating in a weight loss programme; ocular pathology; positive family history of AMD (given the previously established compromised relationship between serum carotenoids and MPOD in this subgroup).

\section{Weight-loss intervention programme}

A customised weight loss plan was provided to each subject randomised to the I group of the study as follows: dietary intervention; exercise intervention; motivational lectures; weekly weight checks.

During the 12-month study period, the C group subjects were permitted to take any steps necessary to achieve weight loss in a personal capacity; however, we did not actively encourage or discourage weight loss in these subjects.

Dietary intervention. Before attending their baseline study visit, all subjects were asked to complete a $7 \mathrm{~d}$ food diary. The weight-loss intervention programme was initiated for subjects randomised to the I group only by a one-to-one consultation with the study dietitian (I. G.; Waterford Regional Hospital). This consultation was held immediately after the baseline study visit (average time after baseline visit, approximately $3 \mathrm{~d}$ ). Using the information obtained from the food diary, the study dietitian advised the I group subjects on customised dietary changes to achieve weight loss.

Using the British Dietetic Association 'Weight Wise Plan' (www.bdaweightwise.com), which is a diet plan based on the classic food pyramid model, the study dietitian customised a low-fat and low-energy diet for each subject recruited into the I group. The 'Weight Wise Plan' assumes that women will lose weight by consuming $6300 \mathrm{~kJ} / \mathrm{d}$ $(1500 \mathrm{cal} / \mathrm{d})$ and that men will lose weight by consuming $7560 \mathrm{~kJ} / \mathrm{d}(1800 \mathrm{cal} / \mathrm{d})$, while still maintaining adequate nutrition. For most subjects, it was estimated that a reduction of $2100-2520 \mathrm{~kJ} / \mathrm{d}$ (approximately $500-600 \mathrm{cal} / \mathrm{d}$ ) was required in order to lose the recommended $0.5 \mathrm{~kg}$ (approximately $1 \mathrm{lb}$ ) per week. Compliance to this diet plan was monitored by once monthly completion of $7 d$ food diaries. These diaries were screened and catalogued by the study investigator (M. L. K.).

Exercise intervention. Moderate exercise for $1 \mathrm{~h}$ per day was recommended for all subjects recruited into the I group. Subjects recorded the type, duration and intensity of exercise performed per day on a customised exercise $\log$ form. Compliance to this exercise plan was monitored by once-monthly completion of exercise diaries. Additionally, a series of exercise classes was provided to subjects in the I group (e.g. aerobics and walking classes). These weekly classes were held in 6-week blocks, evenly spread throughout the entire study period to ensure a standardised intervention for all subjects in the I group. Subject attendance to these classes was recorded and used to facilitate discussion in the motivational lectures.

Motivational lectures. A series of educational lectures were arranged each month for all subjects recruited into the I group. The lectures were designed to educate subjects on a range of topics, for example: weight loss and vision; health benefits of optimal nutrition and achieving and maintaining weight loss; exercise and weight loss; the psychology of weight loss motivation. These lectures also allowed for valuable interaction between subjects in the I group.

Weekly weight checks. Subjects in the I group of the study were required to attend the Macular Pigment Research Group's health laboratory every week for a weight check over the 12-month study period. Weekly reminders were sent to all I group subjects using text messages encouraging 
them to attend their weekly weight check. Feedback with regard to weight loss progress was discussed at this weight check visit. The primary goals of these weekly weight checks were to monitor subject progress, maintain subject interest and set new weight loss targets for the week ahead based on their weight loss progress.

\section{Lifestyle/demographic questionnaire}

The following details were recorded for each subject using a lifestyle and demographic questionnaire: demographic data; best corrected visual acuity; personal ophthalmic and medical history; medication use; smoking status (current, past or never), smoking pack-year consumption was also calculated (daily cigarette consumption $\times$ number of years smoked/20); alcohol consumption; iris colour; ethnicity; ocular and dermatological sun sensitivity.

\section{Macular pigment optical density}

MP was measured psychophysically by customised heterochromatic flicker photometry using the Macular Densitometer $^{\mathrm{TM}}$. A detailed description of this MP measurement technique can be found in a recent publication by Kirby et al. ${ }^{(20)}$.

\section{Serum concentrations of lutein and zeaxanthin}

Serum concentrations of $\mathrm{L}$ and $\mathrm{Z}$ were analysed using HPLC. A detailed description of this technique can be found in a recent publication by Loane et al. ${ }^{(21)}$.

DSM Nutritional Products (Basel, Switzerland) provided $\mathrm{L}$ and $\mathrm{Z}$ standards to generate response factors, which were used to calculate serum concentrations of $\mathrm{L}$ and $\mathrm{Z}$. An internal standard, $\alpha$-tocopherol acetate made up in ethanol $(0.25 \mathrm{mg} / \mathrm{l})$, was used to correct for recovery of extractions for HPLC analysis and assist quantification. All chromatograms were integrated manually by drawing a baseline and dropping perpendicular lines to quantify the peaks of interest. All carotenoid peaks were integrated and quantified using Agilent ChemStation software (Pickering, ON, Canada).

\section{Serum lipoprotein profile}

The Alfa Wassermann ACE ${ }^{\circledR}$ Clinical Chemistry System ('RANDOX') was used to quantify the serum concentrations of HDL-cholesterol, LDL-cholesterol, total cholesterol and TAG. A spectrophotometer is a device for measuring light intensity that can measure intensity as a function of the colour, or more specifically, the wavelength of light. A beam of light is passed through a serum sample (in the present study, subject serum samples of $200 \mu \mathrm{l}$ in volume were used), and based on the absorption properties of the compounds within that sample, a specific light intensity will be emitted.

\section{Anthropometric measurements}

Height, weight and BMI. Subjects were required to remove footwear, and height was measured using a standard height measure (the Leicester Height Measure) and recorded in metres. Weight, without footwear, was recorded in $\mathrm{kg}$ using the SECA Model 862 electronic scales (Seca GmbH \& Company, Hamburg, Germany). BMI was calculated as $\mathrm{kg} / \mathrm{m}^{2}$.

Dual-energy X-ray absorptiometry. Dual-energy X-ray absorptiometry is the gold standard in body composition analysis. Percentage of body fat was determined for each subject using this gold standard method, which uses a low radiation dual-energy X-ray absorptiometry scan (Norland XR-46; Norland Medical Systems, Fort Atkinson, WI, USA). Dual-energy X-ray absorptiometry technology, originally developed to measure bone mineral density, can be used for direct assessment of fat mass. The attenuation by tissues of two X-ray intensities was determined and compared with known values for fat and lean tissue.

Subjects were placed lying supine on the dual-energy X-ray absorptiometry bed, ensuring that they were within the scanning limits. A laser diode (red $670 \mathrm{~nm},-0.2 \mathrm{~mW}$ ) was used to mark a point $1 \mathrm{~cm}$ above the centre of the subject's head. The laser dot was then positioned at a point on the abdomen adjacent to the spine and midway between the lowest rib and the iliac crest. The position was marked in the area of maximum soft tissue and no bone. The scan was started, and the subject was scanned from head to toe. Each scan took between 4 and 5 min, depending on the height of the person. A report of scan results was printed and added to the subject file.

\section{FFQ}

Dietary intake was assessed by a self-administered, semiquantitative FFQ developed by the Scottish Collaborative Group at the University of Aberdeen, Scotland, UK, and described previously by O'Connell et al. ${ }^{(22)}$.

\section{Statistical analysis}

Statistical analysis was conducted using the statistical software package SPSS 15. Differences between the I and $\mathrm{C}$ groups were analysed using the independent samples $t$ test (for differences in quantitative variables such as age, height, weight, BMI, etc.) and the Pearson $\chi^{2}$ test (for differences in qualitative variables such as sex and smoking status), as appropriate.

We conducted repeated-measures ANOVA for all dependent variables (body composition, dietary $\mathrm{L}$ and $\mathrm{Z}$, dietary energy and fat, serum $\mathrm{L}$ and $Z$, serum lipoproteins and MPOD) to investigate whether there was a change in any of these variables over the study period associated with group. Of note, parallel body composition data were available for both groups at baseline and 12 months only 
(Fig. 1). The within-subject factor, 'time', thus had just two levels in our analysis (i.e. values at baseline and 12 months). The between-subject factor, 'group', also had two levels (i.e. I or C). Only subjects who attended both their baseline and 12-month visit were included in the repeated-measures statistical analysis, i.e. subjects who dropped out after baseline were excluded.

We also conducted repeated-measures ANOVA for all dependent variables (body composition, dietary $\mathrm{L}$ and $\mathrm{Z}$, serum $\mathrm{L}$ and $\mathrm{Z}$, serum lipoproteins and MPOD) for the I group only, in order to investigate whether there was a change in any of these variables over the study period within this group. As the I group subjects were measured on five separate occasions, each subsequent visit was compared with baseline.

Pearson's correlation coefficients between pairs of dependent variables were obtained for each of the following groups: I group subjects; I group subjects who achieved a reduction in body composition (hereafter denoted as IR); C group subjects.

\section{Results}

\section{Baseline findings}

Age, smoking habits and sex. The mean age of subjects recruited into the study was 46 (SD 11) years. The mean age of subjects recruited into the $\mathrm{I}$ and $\mathrm{C}$ groups was
47 (SD 10) years and 44 (SD 11) years, respectively $(P=0 \cdot 264)$. There were fifty non-smokers, thirty-six past smokers and eighteen current smokers. Smoking status was not significantly different between the I and $\mathrm{C}$ groups $(P=0 \cdot 156)$. The I group consisted of forty-four females and ten males, and the $\mathrm{C}$ group consisted of thirty-four females and sixteen males, with no statistically significant difference between these groups with respect to $\operatorname{sex}(P=0 \cdot 113)$.

The mean values for all anthropometric, dietary, serum and MP variables are presented in Table 2.

Of note, the subject attrition reported herein is slightly higher when compared with other weight loss studies (Fig. 1) ${ }^{(23-25)}$. Also, the following data were not obtained: body fat data (percentage fat and total fat) on seven subjects; dietary intake data on two subjects; serum data on three subjects.

\section{Longitudinal findings}

Comparing differences over time between the intervention and control groups. For all study-dependent variables, repeated-measures ANOVA was conducted with time (baseline and 12 months), as the within-subject factor, and group (I/C), as the between-subjects factor. A significant time $\times$ group interaction, for any dependent variable, indicates that the change in that variable over time differs

Table 2. Repeated-measures analysis of all study variables from baseline to 12 months showing the time $\times$ group interaction (Mean values and standard deviations)

\begin{tabular}{|c|c|c|c|c|c|c|c|c|c|}
\hline \multirow[b]{3}{*}{ Variables } & \multicolumn{4}{|c|}{ Intervention group } & \multicolumn{4}{|c|}{ Control group } & \multirow{3}{*}{$\begin{array}{c}\text { Time } \times \text { group } \\
\text { interaction } \\
P\end{array}$} \\
\hline & \multicolumn{2}{|c|}{ Baseline } & \multicolumn{2}{|c|}{12 months } & \multicolumn{2}{|c|}{ Baseline } & \multicolumn{2}{|c|}{12 months } & \\
\hline & Mean & SD & Mean & SD & Mean & SD & Mean & SD & \\
\hline \multicolumn{10}{|l|}{ Body composition } \\
\hline Wt $(\mathrm{kg})$ & $95 \cdot 8$ & $18 \cdot 7$ & 92.9 & $19 \cdot 7$ & 90.9 & $20 \cdot 1$ & 90.9 & $22 \cdot 1$ & $0.013^{\star}$ \\
\hline BMI $\left(\mathrm{kg} / \mathrm{m}^{2}\right)$ & 34.9 & $6 \cdot 1$ & $34 \cdot 1$ & $6 \cdot 3$ & 32.9 & $4 \cdot 6$ & $32 \cdot 8$ & $5 \cdot 1$ & 0.094 \\
\hline Body fat (\%) & $41 \cdot 7$ & 8.9 & 41.9 & $8 \cdot 1$ & 41.7 & $7 \cdot 8$ & 42.9 & 7.9 & 0.258 \\
\hline Body fat (kg) & 39.7 & 11.5 & $38 \cdot 8$ & 10.9 & 39 & $11 \cdot 3$ & 40.5 & $13 \cdot 2$ & 0.053 \\
\hline \multicolumn{10}{|l|}{ Dietary $L$ and $Z$} \\
\hline $\mathrm{L}(\mathrm{mg} / \mathrm{d})$ & $1 \cdot 7$ & $1 \cdot 3$ & 1.4 & $1 \cdot 1$ & $1 \cdot 7$ & $1 \cdot 3$ & 1.5 & $1 \cdot 3$ & 0.925 \\
\hline $\mathrm{Z}(\mathrm{mg} / \mathrm{d})$ & 0.27 & 0.13 & 0.22 & 0.1 & 0.24 & 0.14 & 0.18 & 0.1 & 0.987 \\
\hline Fat $(g / d) \dagger$ & $144 \cdot 3$ & 64 & $91 \cdot 7$ & 51 & $112 \cdot 6$ & 41 & 99 & 39 & $0.001^{\star}$ \\
\hline Energy (kJ/d) & 14145 & 5599 & 9794 & 4221 & 11911 & 311 & 10521 & 3801 & $0.003^{\star}$ \\
\hline \multicolumn{10}{|l|}{ Serum $L$ and $Z$} \\
\hline $\mathrm{L}(\mu \mathrm{mol} / \mathrm{l})$ & 0.39 & 0.15 & 0.4 & 0.13 & 0.44 & 0.2 & 0.48 & 0.17 & 0.285 \\
\hline $\mathrm{Z}(\mu \mathrm{mol} / \mathrm{l})$ & 0.18 & 0.05 & 0.2 & 0.07 & 0.22 & 0.1 & 0.23 & 0.08 & 0.98 \\
\hline \multicolumn{10}{|l|}{ Serum lipoproteins } \\
\hline Total cholesterol (mmol/l) & 5 & $1 \cdot 3$ & $4 \cdot 8$ & 1 & 5 & $1 \cdot 2$ & $5 \cdot 4$ & 1.3 & 0.058 \\
\hline LDL-cholesterol (mmol/l) & 2.9 & 0.9 & $3 \cdot 2$ & $1 \cdot 1$ & $2 \cdot 7$ & 0.9 & $3 \cdot 6$ & $1 \cdot 15$ & $0.010^{\star}$ \\
\hline HDL-cholesterol (mmol/l) & $1 \cdot 23$ & 0.39 & $1 \cdot 35$ & 0.35 & $1 \cdot 15$ & 0.41 & 1.41 & 0.49 & 0.213 \\
\hline TAG $(\mathrm{mmol} / \mathrm{l}) \dagger$ & 1.32 & 0.63 & $1 \cdot 2$ & 0.53 & $1 \cdot 7$ & $1 \cdot 36$ & $1 \cdot 71$ & 1.07 & 0.501 \\
\hline \multicolumn{10}{|l|}{ MPOD } \\
\hline $0.25^{\circ} \ddagger$ & 0.48 & 0.22 & 0.48 & 0.22 & 0.52 & 0.18 & 0.53 & $0 \cdot 18$ & 0.887 \\
\hline $0.5^{\circ}$ & 0.4 & 0.2 & 0.4 & 0.2 & 0.42 & 0.16 & 0.44 & 0.18 & 0.218 \\
\hline $1 \cdot 0^{\circ}$ & 0.27 & 0.14 & $0 \cdot 25$ & 0.15 & $0 \cdot 28$ & 0.14 & 0.28 & 0.14 & 0.389 \\
\hline $1.75^{\circ}$ & 0.16 & 0.11 & 0.13 & $0 \cdot 1$ & 0.19 & 0.12 & 0.17 & 0.12 & 0.703 \\
\hline
\end{tabular}

L, lutein; Z, zeaxanthin; MPOD, macular pigment optical density.

* Significant at the 0.05 level (two-tailed).

$\dagger$ Significant difference between groups at baseline at the 0.05 level.

$\ddagger$ Degrees of retinal eccentricity. 
between the I and $C$ groups. Results for the different dependent variables, including $P$ values for the time $\times$ group interactions, are displayed in Table 2 .

Body composition variables. Mean weight dropped by $2.9 \mathrm{~kg}$ in the I group and by $0.0 \mathrm{~kg}$ in the $\mathrm{C}$ group, resulting in a statistically significant time $\times$ group interaction effect (Table $2 ; P=0 \cdot 01$ ). Body fat dropped by $0.9 \mathrm{~kg}$ $(2.3 \%)$ in the I group and increased by $1.5 \mathrm{~kg}(3.7 \%)$ in the $\mathrm{C}$ group, resulting in a borderline statistically significant time $\times$ group interaction effect $(P=0 \cdot 05)$. Declines in mean BMI and percentage body fat were also greater in the I group, but not significantly so.

Dietary lutein and zeaxanthin. There was no statistically significant time $\times$ group interaction effect between the I and the $\mathrm{C}$ groups for dietary $\mathrm{L}$ or dietary $\mathrm{Z}$ (Table 2; $P>0.05$ for all).

Serum concentrations of lutein and zeaxanthin. There was no statistically significant time $\times$ group interaction effect between the I and $\mathrm{C}$ groups for serum L or serum $\mathrm{Z}$ (Table $2 ; P>0.05$ for all)

Serum lipoproteins. Over the 12-month study period, mean LDL increased by $0.3(\mathrm{mmol} / \mathrm{l})$ in the I group and by $0.7(\mathrm{mmol} / \mathrm{l})$ in the $\mathrm{C}$ group, resulting in a statistically significant time $\times$ group interaction effect (Table 2, $P=0 \cdot 01)$. Changes in other serum lipoprotein variables did not differ significantly between the I and $\mathrm{C}$ groups.

Macular pigment optical density. Changes in MPOD over the 12-month study period did not differ significantly between the I and the $\mathrm{C}$ groups. This was the case at each degree of retinal eccentricity measured, i.e. $0 \cdot 25^{\circ}, 0.5^{\circ}, 1 \cdot 0^{\circ}$ and $1.75^{\circ}$ (Table $2 ; P>0.05$ for all).

Analysing variables over time for the intervention group only. The results of repeated-measures analysis of all study variables, for the I group, are presented in Tables 3 and 4 .

\section{Relationships between changes in dependent variables} (intervention group subjects)

Changes in the serum concentrations of lutein and zeaxanthin with respect to changes in body composition variables Intervention group. There was no statistically significant relationship between changes in the serum concentrations of L (i.e. 12-month - baseline values) and changes in weight or BMI (baseline - 12 month values) ( $r$ 0.27$0.32 ; P>0.05$ for all). There was a statistically significant relationship between changes in the serum concentrations of $\mathrm{L}$ and changes in percentage body fat at 12 months ( $r$ 0.55; $P=0.00)$, which remained after controlling for dietary intake of $\mathrm{L}(r 0.54 ; P=0.00)$. There was a statistically significant positive relationship between changes in the serum concentrations of $\mathrm{L}$ and changes in body fat $(\mathrm{kg})$ at 12 months $(r 0.52 ; P=0.00 ;$ Fig. 2$)$, which remained statistically significant after controlling for dietary intake of $\mathrm{L}(r 0.55 ; P=0.01)$. There was no statistically significant relationship between changes in the serum concentrations of $\mathrm{Z}$ and changes in any of the body composition variables measured at 12 months ( $P>0.05$ for all).

Intervention group subjects who achieved a reduction in body composition. For this group, the relationships between changes in the serum concentrations of $\mathrm{L}$ and $\mathrm{Z}$ with respect to changes in weight, BMI, percentage body fat and fat mass are presented in Table 5. Changes in the serum concentrations of L (i.e. 12-month - baseline values) were positively and significantly correlated with changes in the following body composition variables (baseline - 12-month values): weight, BMI, percentage body fat and fat mass, but this was not the case for changes in serum $Z$ (Table 5, columns 2 and 3).

The relationships between weight loss $(\mathrm{kg})$ and changes in the serum concentrations of $\mathrm{L}$, and between body fat loss $(\mathrm{kg})$ and changes in the serum concentrations of $\mathrm{L}$, are graphically presented in Figs. 3 and 4.

Changes in macular pigment optical density, at all eccentricities measured, with respect to changes in body composition variables

Intervention group. There was no statistically significant relationship between changes in MPOD (i.e. 12-month baseline values) at any degree of retinal eccentricity measured and changes in weight, BMI, percentage body fat or body fat ( $\mathrm{kg}$ ) (baseline - 12-month values) throughout the study period for the I group ( $P>0.05$ for all).

Intervention group subjects who achieved a reduction in body composition. There was no statistically significant relationship between changes in MPOD (i.e. 12-month baseline values) at any degree of retinal eccentricity

Table 3. Mean body composition values at each study visit for the intervention group (Mean values and standard deviations)

\begin{tabular}{|c|c|c|c|c|c|c|c|c|c|c|}
\hline & \multicolumn{2}{|c|}{ Baseline } & \multicolumn{2}{|c|}{1 month } & \multicolumn{2}{|c|}{3 months } & \multicolumn{2}{|c|}{6 months } & \multicolumn{2}{|c|}{12 months } \\
\hline & Mean & SD & Mean & SD & Mean & SD & Mean & SD & Mean & SD \\
\hline Wt (kg) & $96 \cdot 5$ & $20 \cdot 2$ & $94.8^{\star}$ & 20.6 & $93.5^{\star}$ & $21 \cdot 7$ & $92 \cdot 9^{\star}$ & $21 \cdot 2$ & $93.3 \dagger$ & $21 \cdot 2$ \\
\hline BMI $\left(\mathrm{kg} / \mathrm{m}^{2}\right)$ & $35 \cdot 3$ & 6.5 & $34 \cdot 8^{\star}$ & 6.6 & $34.3^{*}$ & 6.9 & $34^{\star}$ & 6.7 & $34.2 \dagger$ & 6.6 \\
\hline Body fat (\%) & 41.9 & 9.4 & $\mathrm{n} / \mathrm{a}$ & $\mathrm{n} / \mathrm{a}$ & $\mathrm{n} / \mathrm{a}$ & $\mathrm{n} / \mathrm{a}$ & $40 \cdot 6$ & 9.8 & $41 \cdot 2$ & 8.9 \\
\hline Body fat $(\mathrm{kg})$ & $40 \cdot 3$ & $12 \cdot 8$ & $n / a$ & $n / a$ & $n / a$ & $n / a$ & $37.7 \dagger$ & 13 & 38.6 & $12 \cdot 6$ \\
\hline
\end{tabular}

$\mathrm{n} / \mathrm{a}$, No study visit.

${ }^{*}$ A statistically significant difference at the 0.01 level (two-tailed) between baseline and the indicated time point.

† A statistically significant difference at the 0.05 level (two-tailed) between baseline and the indicated time point. 
Table 4. Dietary, serum and macular pigment optical density (MPOD) variables at each study visit for the intervention group (Mean values and standard deviations)

\begin{tabular}{|c|c|c|c|c|c|c|c|c|c|c|}
\hline & \multicolumn{2}{|c|}{ Baseline } & \multicolumn{2}{|c|}{1 month } & \multicolumn{2}{|c|}{3 months } & \multicolumn{2}{|c|}{6 months } & \multicolumn{2}{|c|}{12 months } \\
\hline & Mean & SD & Mean & SD & Mean & SD & Mean & SD & Mean & SD \\
\hline Dietary L & $1 \cdot 8$ & 1.4 & $\mathrm{n} / \mathrm{a}$ & $\mathrm{n} / \mathrm{a}$ & 2 & $2 \cdot 1$ & 1.6 & 1.5 & 1.5 & $1 \cdot 1$ \\
\hline Dietary Z & 0.29 & 0.14 & $\mathrm{n} / \mathrm{a}$ & $\mathrm{n} / \mathrm{a}$ & 0.25 & 0.18 & 0.25 & 0.18 & $0.23^{*}$ & 0.1 \\
\hline Serum L & 0.39 & 0.15 & 0.4 & 0.18 & 0.41 & 0.15 & 0.41 & 0.22 & 0.4 & 0.14 \\
\hline Serum Z & $0 \cdot 18$ & 0.06 & 0.2 & 0.01 & 0.2 & 0.01 & 0.18 & 0.07 & 0.21 & 0.08 \\
\hline Total cholesterol & 4.9 & 1.3 & 4.8 & 1.3 & $4 \cdot 3^{*}$ & 1 & 4.5 & 1 & $4 \cdot 8$ & 1 \\
\hline HDL-cholesterol & 1.2 & 0.4 & $1 \cdot 1$ & 0.3 & $1.0^{*}$ & 0.4 & $1 \cdot 2$ & 0.4 & 1.3 & 0.4 \\
\hline LDL-cholesterol & $2 \cdot 8$ & 0.8 & $2 \cdot 7$ & 1 & $2 \cdot 3^{\star}$ & 0.7 & 2.9 & 1 & $3 \cdot 1$ & 1 \\
\hline TAG & 1.4 & 0.6 & 1.2 & 0.5 & $1.0 \dagger$ & 0.4 & 1.2 & 0.5 & 1.3 & 0.6 \\
\hline \multicolumn{11}{|l|}{ MPOD } \\
\hline $0.25^{\circ}$ & 0.48 & 0.22 & 0.46 & 0.22 & 0.48 & 0.23 & 0.48 & 0.2 & 0.49 & 0.2 \\
\hline $0.5^{\circ}$ & 0.4 & 0.2 & 0.39 & 0.2 & 0.37 & 0.2 & 0.38 & 0.19 & 0.4 & 0.18 \\
\hline $1.0^{\circ}$ & 0.27 & 0.15 & 0.25 & 0.15 & 0.24 & 0.15 & $0.24^{*}$ & 0.15 & 0.26 & 0.15 \\
\hline $1.75^{\circ}$ & 0.16 & 0.11 & 0.14 & 0.1 & $0.11^{*}$ & 0.1 & $0.12^{*}$ & 0.1 & 0.13 & 0.1 \\
\hline
\end{tabular}

measured and changes in weight, BMI, percentage body fat or body fat (kg) (baseline - 12-month values) throughout the study period for the IR group (i.e. subjects who achieved a reduction in body composition) ( $P>0.05$ for all).

\section{Discussion}

The present study was designed to investigate whether weight loss alters MPOD and/or the serum concentrations of its constituent carotenoids. We report that, on average, subjects in the I group lost a statistically significant amount of weight over the study period $(2.9(\mathrm{SD} 5.3) \mathrm{kg})$, evident at just 1 month from baseline $(1.67$ (SD 1.7) kg). Maximum weight loss in the I group was achieved at 6 months $(3.02(\mathrm{SD} 4.1) \mathrm{kg})$, after which there was a slight increase $(0.57(\mathrm{SD} 4.3) \mathrm{kg})$ in the average weight of this group from this time point. Our findings are largely consistent with other studies which have attempted to achieve weight loss over a similar time period ${ }^{(24,26)}$. The observed slight weight increase between 6 and 12 months is also consistent with other studies of similar design $^{(27,28)}$. As expected, average body composition values in the $\mathrm{C}$ group did not change significantly over the study period, even though the present study design did not prevent the $\mathrm{C}$ group subjects from attempting to lose weight over the study period by their own means. This is consistent with previous randomised controlled weight loss studies, which have demonstrated that subjects randomised to a control or 'no advice' category tend to lose less, or no, weight in comparison with subjects who are enrolled in the intervention $\operatorname{arm}^{(29,30)}$.

While a detailed dietary assessment (by an FFQ) demonstrated a significant reduction in the dietary intake of total energy and total fat in both groups over the study period, these reductions were approximately three times greater in the I group, when compared with the $\mathrm{C}$ group. We found that, for the I group, reductions in the dietary intake of total energy and total fat paralleled the weight loss achieved for these subjects. Interestingly, and somewhat surprisingly, there was no significant change in the dietary intake of $\mathrm{L}$ or $\mathrm{Z}$ in the I group over the study period. As expected, however, dietary intake of $\mathrm{L}$ and $\mathrm{Z}$ remained stable (i.e. statistically comparable at baseline and 12 months) in the $\mathrm{C}$ group.

We report no statistically significant change in serum concentrations of $\mathrm{L}$ or $\mathrm{Z}$, in either group, over the study period. Similarly, when only the IR group subjects (i.e. subjects who achieved a reduction in body composition) were analysed separately, there was no significant change in serum concentrations of L or Z. Noteworthy, however, was the increasing trend observed in serum concentrations of $\mathrm{L}$ for the I group between baseline and 6 months $(7 \cdot 8 \%$ increase); however, as mentioned above, this did not reach statistical significance. While not statistically significant, it is important to note that this trend was in the exact opposite

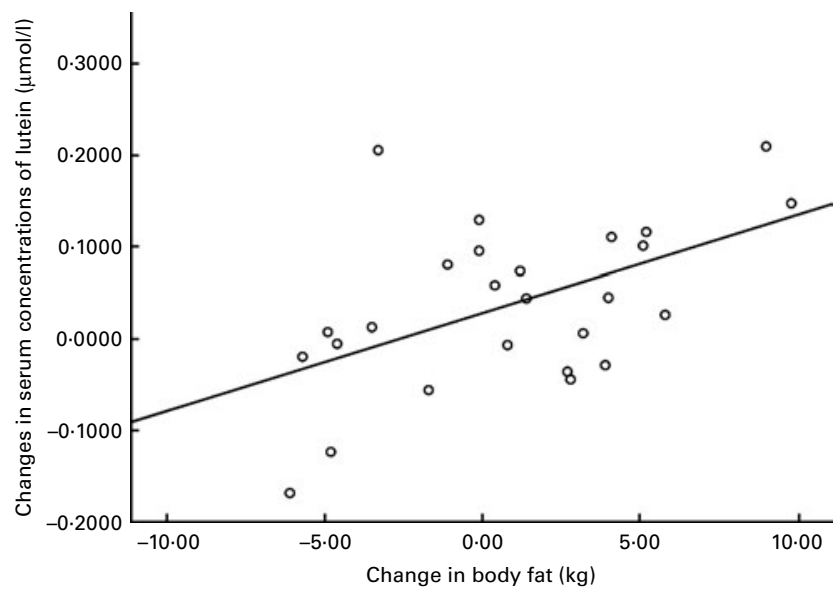

Fig. 2. Changes in serum concentrations of lutein $v$. changes in body fat at 12 months for the intervention group only. 
Table 5. Pearson's correlation matrix showing the relationship between changes in serum concentrations of lutein $(L)$ and zeaxanthin (Z) and changes in body composition measurements for the IR group*

\begin{tabular}{|c|c|c|c|c|c|c|}
\hline & $\begin{array}{c}\text { Changes in } \\
\text { serum L† }\end{array}$ & $\begin{array}{c}\text { Changes in } \\
\text { serum Z } \neq\end{array}$ & $\begin{array}{l}\text { Changes } \\
\text { in wt (kg) }\end{array}$ & $\begin{array}{l}\text { Changes in } \\
\text { BMI }\left(\mathrm{kg} / \mathrm{m}^{2}\right)\end{array}$ & $\begin{array}{l}\text { Changes in } \\
\text { body fat (\%) }\end{array}$ & $\begin{array}{l}\text { Changes in } \\
\text { body fat (kg) }\end{array}$ \\
\hline Changes in serum $L(\mu \mathrm{mol} / /)$ & 1 & & & & & \\
\hline Changes in serum $\mathrm{Z}(\mu \mathrm{mol} / \mathrm{l})$ & $0.619 \S$ & 1 & & & & \\
\hline Changes in wt $(\mathrm{kg})$ & $0.479 \S$ & 0.189 & 1 & & & \\
\hline Changes in BMI $\left(\mathrm{kg} / \mathrm{m}^{2}\right)$ & $0.506 \S$ & 0.200 & $0.976 \|$ & 1 & & \\
\hline Changes in body fat (\%) & $0.730 \|$ & 0.421 & $0.481 \S$ & $0.473 \S$ & 1 & \\
\hline Changes in body fat $(\mathrm{kg})$ & $0.653 \|$ & 0.301 & $0 \cdot 868 \|$ & $0.849 \|$ & $0.702 \S$ & 1 \\
\hline
\end{tabular}

* IR group, subjects within the intervention group who achieved a reduction in body composition.

$\dagger$ Controlling for dietary intake of $L$.

$\ddagger$ Controlling for dietary intake of $Z$.

|| Correlation is significant at the 0.01 level (two-tailed).

$\S$ Correlation is significant at the 0.05 level (two-tailed).

direction to the observed changes seen in weight over the study period (i.e. as average weight decreased, average serum L concentrations increased). However, our primary statistical conclusion, with respect to serum $\mathrm{L}$ and $\mathrm{Z}$ concentrations, is that the weight loss achieved in the present study did not result in a significant change in serum concentrations of either of the macular carotenoids. It should be noted that a positive family history of AMD was an exclusion criterion in the present study. This is of importance to the present discussion, as a recent study by our group has shown a compromised relationship between serum carotenoids and MPOD in subjects with a positive family history of $\mathrm{AMD}^{(31)}$. Specifically, such subjects demonstrate no statistically significant relationship between serum $\mathrm{Z}$ and MPOD, in contrast to the positive and significant relationship between these two variables in subjects without a family history of AMD. In the light of this already identified compromised relationship, subjects with a positive family history of AMD were excluded from the present investigation.

Consistent with the above findings, we report no statistically significant change in MPOD, at any of the degrees of eccentricity measured, in either group over the study period. Similarly, when only the IR group subjects were analysed separately, there was no statistically significant change observed in average MPOD at any eccentricity measured for these subjects.

The above primary findings are not surprising in the context of the present study for the following reasons. First, subjects in the I group lost only a moderate amount of weight over the study period (BMI in the I group decreased by approximately $1(\mathrm{SD} 2) \mathrm{kg} / \mathrm{m}^{2}$ ), and it is possible, therefore, that greater weight loss in this group may have resulted in significant changes in serum concentrations of $\mathrm{L}$ and/or $\mathrm{Z}$, and (given the well-established and known positive relationship between serum $\mathrm{L}$ and MPOD) consequential changes in $\mathrm{MPOD}^{(32)}$. Second, neither dietary nor serum concentrations of $\mathrm{L}$ and $\mathrm{Z}$ changed significantly over the study period, and it is likely that the increase seen in serum concentrations of $\mathrm{L}$ from baseline to 6 months (seen only in the I group of the present study) was insufficient to have an effect on MPOD, at any of the eccentricities measured (i.e. on average, serum L increased by only $0.01 \mu \mathrm{mol} / 1 \quad(7 \cdot 8 \%$ from baseline)). Consistent with this, a previous study by Nolan et $a l .{ }^{(33)}$ demonstrated the stability of MP over a 24-month study period, in healthy subjects, in the absence of changes in dietary and/or serum concentrations of $\mathrm{L}$ and $\mathrm{Z}$. To put this in context, a recent $\mathrm{L}$ supplementation study ( $12 \mathrm{mg}$ of $\mathrm{L} / \mathrm{d}$ for 6 months) performed by Trieschmann et $a l^{(34)}$ found that serum concentrations of $\mathrm{L}$ increased by approximately $270 \%$, which resulted in an increase of only 0.1 (SD 0.009) MPOD units. In other words, while this weight loss intervention study did result in changes in serum concentrations of L (albeit non-significant), it is unlikely that these changes in serum L concentrations were sufficient to alter I subjects' MPOD.

Of note, we did not find a relationship between diet and MPOD in the present study. This finding was somewhat unexpected. While the precise cause of this discrepancy is difficult to explain, it is possible that the nature of our cohort, i.e. overweight and predominantly female, may have contributed to an attenuated normal and positive relationship between diet and MPOD. Previous studies have demonstrated sex differences in the metabolism of $\mathrm{L}$ (i.e. the relationship between diet, serum, adipose tissue

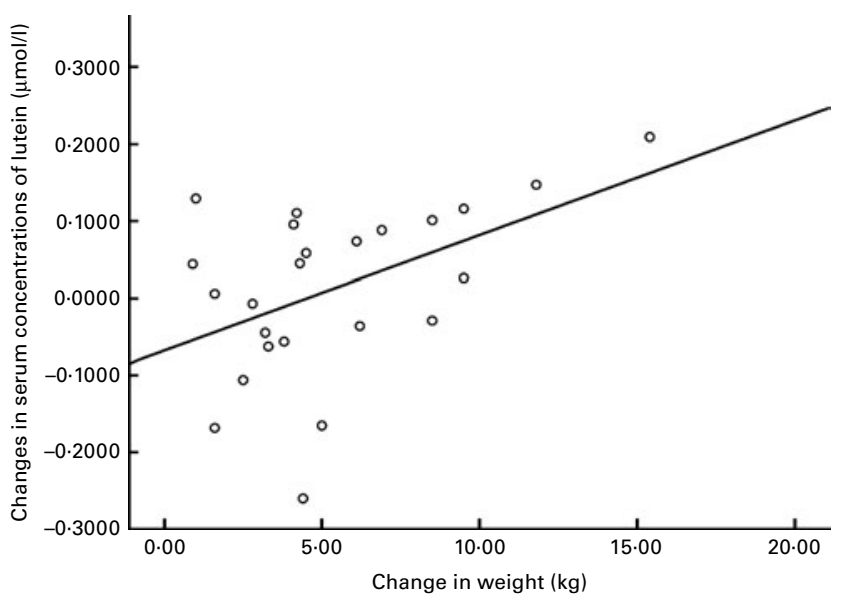

Fig. 3. Changes in serum concentrations of lutein $v$. changes in weight at 12 months for the intervention group subjects who achieved a reduction in body composition. 


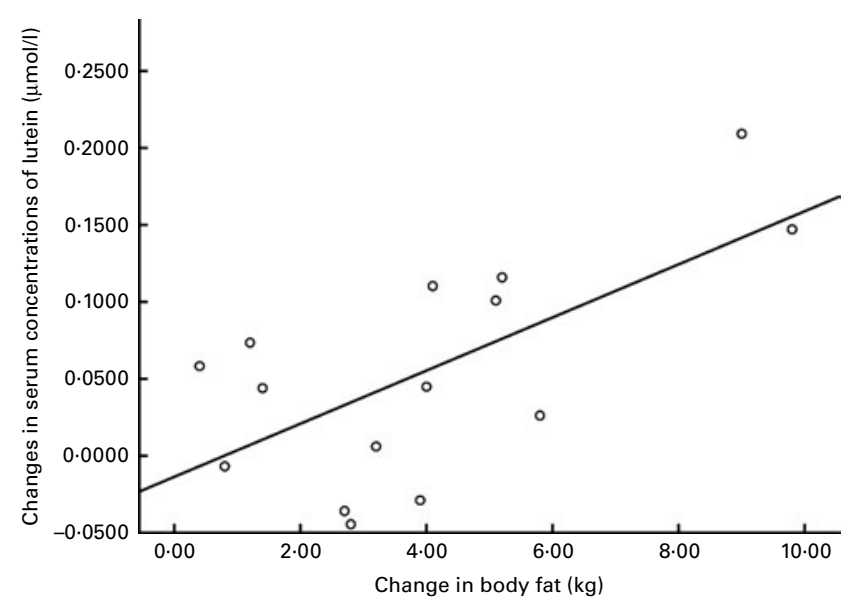

Fig. 4. Changes in serum concentrations of lutein $v$. changes in body fat at 12 months for the intervention group subjects who achieved a reduction in body composition.

and macular levels of carotenoids ${ }^{(35,36)}$. Furthermore, it has been suggested that obesity may further confound the normal relationship between diet and MPOD ${ }^{(16)}$. Alternatively, this discrepancy may be explained by a weakness in our FFQ. It is possible that our questionnaire may have been insufficiently sensitive to determine precise carotenoid intake. This may have led to an underestimation of dietary L intake and, consequentially, a weakened relationship between diet and MPOD.

A secondary outcome measure for the present study was the relationship, if any, between changes in body composition with respect to changes in serum concentrations of L. Firstly, we report a positive and statistically significant relationship between changes in body fat (kg and percentage) and changes in serum concentrations of $\mathrm{L}$ in the I group. Furthermore, analysing subjects in the I group who achieved a reduction in body composition ( $n$ 25) resulted in an even stronger positive and statistically significant relationship between changes in all body composition variables and changes in serum concentrations of $\mathrm{L}$.

This interesting and novel finding is consistent with the 'body fat carotenoid reservoir' hypothesis originally proposed by Hammond et $a l^{(13)}$, which is of particular importance for overweight and obese subjects, given that up to $80 \%$ of total carotenoids in the human body are stored in the body fat ${ }^{(37)}$. Indeed, this hypothesis is also supported by the baseline findings of the present study, in addition to several other studies, which demonstrate

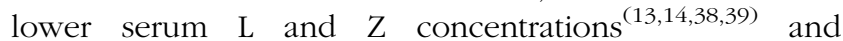
$\operatorname{MPOD}^{(13,14,36)}$ in subjects with higher body composition measurements. To explain these findings, Hammond et al., and later Nolan et al., discussed the possibility that competition exists between body fat and other host tissues, such as the macula, for circulating carotenoids. The present study was designed to investigate this hypothesis further by testing whether weight loss resulted in increased circulating levels of the macular carotenoids (as it is likely that these carotenoids would be released into the serum following weight loss) $)^{(16,35)}$. Our findings are also consistent with those of $\mathrm{Kant}^{(40)}$ (data from the third National Health and Nutrition Examination Survey) who reported higher serum concentrations of $\mathrm{L}$ and $\mathrm{Z}$ in subjects attempting to lose weight. To our knowledge, however, our finding is novel in that it is the first study to show an effect of weight loss on changes in serum concentrations of $\mathrm{L}$, in a well-designed, weight loss intervention controlled study, as opposed to the previous and limited (in terms of study design) cross-sectional studies. The relationship between changes in body composition with respect to changes in MPOD was also assessed as a secondary outcome measure, and unsurprisingly (as discussed above), we found no statistically significant relationship between weight loss, BMI reduction or body fat loss ( $\mathrm{kg}$ and percentage) and changes in MPOD at any of the eccentricities measured.

Another goal of the present study was to investigate the relationship, if any, between circulating serum lipoproteins and MPOD, and their response to weight loss, in overweight and obese subjects. As previously explained, L and $\mathrm{Z}$ are transported in circulating serum lipoproteins ${ }^{(41)}$. It seems plausible to suggest, therefore, that a decrease in the level of circulating lipoproteins (e.g. as seen in association with weight loss) might result in a decrease in serum carotenoid concentrations (and, consequentially, a decrease in MPOD). Interestingly, two recent studies, which investigate the effect of altering the level of circulating lipoproteins with respect to serum carotenoids concentrations, have reported a reduction in serum concentrations of these nutrients. Briefly, Berendschot et $a l .{ }^{(42)}$ reported a significant reduction in serum $\mathrm{L}$ and $\mathrm{Z}$ concentrations following the use of a functional food containing plant stanols (plant stanols have been shown to lower circulating lipoprotein levels). It should be noted, however, that Berendschot et al. observed no change in MP despite these changes in serum concentrations of $\mathrm{L}$ and $\mathrm{Z}$. Similarly, Neuhouser et al. ${ }^{(43)}$ reported a decrease in serum carotenoid concentrations following the use of a fat substitute product (i.e. a fat substitute which is not absorbed by the gut, and would therefore lead to lower circulating lipoprotein levels). Collectively, these findings provide a foundation to the hypothesis that serum carotenoids and MPOD may be influenced by a decrease in circulating lipoprotein levels, following weight loss.

In the present study, we report a statistically significant decrease in total cholesterol, HDL-cholesterol, LDL-cholesterol and TAG at 3 months in the I group. At 12 months, however, there was no statistically significant difference in the concentration of any of these lipoproteins to baseline values. More importantly, and somewhat surprisingly, there was no change in the ratio of LDL:HDL-cholesterol over the study period in either group. Also, we report no statistically significant relationship between any of the 
serum lipoproteins (or changes in these variables at any time point) and the serum concentrations of $\mathrm{L}$ and $\mathrm{Z}$, or MPOD (or changes in these variables at any time point). This finding was unexpected, as it has been shown that carotenoids transported on HDL-cholesterol are more efficiently captured by the retina due to the unique binding affinity of its associated apolipoprotein ${ }^{(44)}$. In other words, one would expect a positive and significant relationship between HDL-cholesterol and MPOD. The lack of such a relationship in the present study is therefore difficult to explain. It is possible that the nature of our cohort, i.e. all overweight or obese, may have biased the present results. Indeed, the average BMI of our baseline cohort was $34 \mathrm{~kg} / \mathrm{m}^{2}$, and it has been well documented that such subjects have an unfavourable lipoprotein profile (i.e. a high LDL:HDL ratio) ${ }^{(17)}$. In other words, if there was a high overall ratio of LDL:HDL for the entire cohort, a relationship with MPOD may have been much weaker than in a cohort of subjects with a healthy average BMI. In addition, and as discussed above, greater weight loss in the I group may have resulted in significant changes in the lipoprotein profile and allowed for an appropriate investigation into the relationships, if any, between HDL-cholesterol, serum carotenoids and MPOD in this population.

To conclude, our weight loss intervention was successful in that significant weight loss was achieved in the I group of the study. However, there was no statistically significant change in average serum concentrations of $\mathrm{L}$ and $\mathrm{Z}$ in the I group over the study period, which explains (at least in part) the lack of a change seen in MPOD at any retinal eccentricity measured in the I group over the study period. We do, however, report a novel positive and statistically significant relationship between the reduction in body composition and the increases in serum concentrations of $\mathrm{L}$. This finding is provocative, given the published putative association between obesity and $\mathrm{AMD}^{(45-48)}$, and is consistent with the hypothesis that body fat acts as a reservoir for the macular carotenoids, and that weight loss can positively influence circulating carotenoid levels. Further study is warranted to fully understand the potential for weight loss in reducing the risk of AMD in overweight and obese individuals.

\section{Acknowledgements}

We would like to acknowledge the Medical Research Charities Group in Ireland; Fighting Blindness, Ireland and the Health Research Board, Ireland, who kindly supported the present study. We also list the following disclosures: M. L. K., none; M. H., none; I. G., none; S. M., none. S. B. and J. M. N. do consultancy work for nutraceutical companies in a personal capacity, and as directors of Nutrasight Consultancy Limited. The author contributions were as follows: M. L. K. investigated the study; S. B. designed and supervised the study; J. S. gave statistical advice; M. H. coordinated the weight loss programme; I. G. gave dietary advice; S. M. gave motivational lectures; P. C. conducted weight loss classes and J. M. N. designed and supervised the study.

\section{References}

1. Sommerburg O, Keunen JEE, Bird AC, et al. (1998) Fruits and vegetables that are sources for lutein and zeaxanthin: the macular pigment in human eyes. Br J Ophthalmol $\mathbf{8 2}$, 907-910

2. Kaplan LA, Lau JM \& Stein EA (1990) Carotenoid composition, concentrations, and relationships in various human organs. Clin Physiol Biochem 8, 1-10.

3. Bone RA, Landrum JT \& Tarsis SL (1985) Preliminary identification of the human macular pigment. Vision Res 25 , $1531-1535$.

4. Bone RA, Landrum JT, Hime GW, et al. (1993) Stereochemistry of the human macular carotenoids. Invest Ophthalmol Vis Sci 34, 2033-2040.

5. Congdon N, O'Colmain B, Klaver CC, et al. (2004) Causes and prevalence of visual impairment among adults in the United States. Arch Ophthalmol 122, 477-485.

6. Hollyfield JG, Bonilha VL, Rayborn ME, et al. (2008) Oxidative damage-induced inflammation initiates age-related macular degeneration. Nat Med 14, 194-198.

7. Izumi-Nagai K, Nagai N, Ohgami K, et al. (2007) Macular pigment lutein is antiinflammatory in preventing choroidal neovascularization. Arterioscler Thromb Vasc Biol 27, $2555-2562$.

8. Loane E, Kelliher C, Beatty S, et al. (2008) The rationale and evidence base for a protective role of macular pigment in age-related maculopathy. Br J Ophthalmol 92, $1163-1168$.

9. Stringham JM \& Hammond BR Jr (2005) Dietary lutein and zeaxanthin: possible effects on visual function. Nutr Rev 63, 59-64.

10. Caballero B (2007) The global epidemic of obesity: an overview. Epidemiol Rev 29, 1-5.

11. Hedley AA, Ogden CL, Johnson CL, et al. (2004) Prevalence of overweight and obesity among US children, adolescents, and adults, 1999-2002. JAMA 291, 2847-2850.

12. Parker RS (1989) Carotenoids in human-blood and tissues. J Nutr 119, 101-104

13. Hammond BR, Ciulla TA \& Snodderly DM (2002) Macular pigment density is reduced in obese subjects. Invest Ophthalmol Vis Sci 43, 47-50.

14. Nolan J, O’Donovan O, Kavanagh H, et al. (2004) Macular pigment and percentage of body fat. Invest Ophthalmol Vis Sci 45, 3940-3950.

15. Peeters A, Magliano DJ, Stevens J, et al. (2008) Changes in abdominal obesity and age-related macular degeneration: the Atherosclerosis Risk in Communities Study. Arch Ophthalmol 126, 1554-1560.

16. Johnson EJ (2005) Obesity, lutein metabolism, and agerelated macular degeneration: a web of connections. Nutr Rev 63, 9-15.

17. Viroonudomphol D, Pongpaew $\mathrm{P}$, Tungtrongchitr R, et al. (2003) The relationships between anthropometric measurements, serum vitamin A and E concentrations and lipid profiles in overweight and obese subjects. Asia Pac J Clin Nutr 12, 73-79

18. Zwiauer K, Widhalm K \& Kerbl B (1990) Relationship between body fat distribution and blood lipids in obese adolescents. Int J Obes 14, 271-277. 
19. Berg CM, Lappas G, Strandhagen E, et al. (2008) Food patterns and cardiovascular disease risk factors: the Swedish INTERGENE research program. Am J Clin Nutr 88, 289-297.

20. Kirby ML, Galea M, Loane E, et al. (2009) Foveal anatomic associations with the secondary peak and the slope of the macular pigment spatial profile. Invest Ophthalmol Vis Sci 50, 1383-1391.

21. Loane E, McKay GJ, Nolan JM, et al. (2010) Apolipoprotein E genotype is associated with macular pigment optical density. Invest Ophthalmol Vis Sci 51, 2636-2643.

22. O'Connell ED, Nolan JM, Stack J, et al. (2008) Diet and risk factors for age-related maculopathy. Am J Clin Nutr 87, $712-722$.

23. Greenberg I, Stampfer MJ, Schwarzfuchs D, et al. (2009) Adherence and success in long-term weight loss diets: the dietary intervention randomized controlled trial (DIRECT). J Am Coll Nutr 28, 159-168.

24. Frisch S, Zittermann A, Berthold HK, et al. (2009) A randomized controlled trial on the efficacy of carbohydrate-reduced or fat-reduced diets in patients attending a telemedically guided weight loss program. Cardiovasc Diabetol 8, 36.

25. Jehn ML, Patt MR, Appel LJ, et al. (2006) One year follow-up of overweight and obese hypertensive adults following intensive lifestyle therapy. J Hum Nutr Diet 19, 349-354.

26. Azadbakht L, Mirmiran P, Esmaillzadeh A, et al. (2007) Better dietary adherence and weight maintenance achieved by a long-term moderate-fat diet. Br J Nutr 97, 399-404.

27. Sacks FM, Bray GA, Carey VJ, et al. (2009) Comparison of weight-loss diets with different compositions of fat, protein, and carbohydrates. $N$ Engl J Med 360, 859-873.

28. Volpe SL, Kobusingye H, Bailur S, et al. (2008) Effect of diet and exercise on body composition, energy intake and leptin levels in overweight women and men. J Am Coll Nutr 27, $195-208$

29. Kirkwood L, Aldujaili E \& Drummond S (2007) Effects of advice on dietary intake and/or physical activity on body composition, blood lipids and insulin resistance following a low-fat, sucrose-containing, high-carbohydrate, energyrestricted diet. Int J Food Sci Nutr 58, 383-397.

30. Jenkinson CM, Doherty M, Avery AJ, et al. (2009) Effects of dietary intervention and quadriceps strengthening exercises on pain and function in overweight people with knee pain: randomised controlled trial. BMJ 339, b3170.

31. Nolan JM, Stack J, O'Connell E, et al. (2007) The relationships between macular pigment optical density and its constituent carotenoids in diet and serum. Invest Ophthalmol Vis Sci 48, 571-582.

32. Curran-Celentano J, Hammond BR, Ciulla TA, et al. (2001) Relation between dietary intake, serum concentrations, and retinal concentrations of lutein and zeaxanthin in adults in a Midwest population. Am J Clin Nutr 74, 796-802.

33. Nolan JM, Stack J, Mellerio J, et al. (2006) Monthly consistency of macular pigment optical density and serum concentrations of lutein and zeaxanthin. Curr Eye Res 31, $199-213$

34. Trieschmann M, Beatty S, Nolan JM, et al. (2007) Changes in macular pigment optical density and serum concentrations of its constituent carotenoids following supplemental lutein and zeaxanthin: the LUNA study. Exp Eye Res 84, $718-728$.

35. Johnson EJ, Hammond BR, Yeum KJ, et al. (2000) Relation among serum and tissue concentrations of lutein and zeaxanthin and macular pigment density. Am J Clin Nutr 71, $1555-1562$.

36. Broekmans WMR, Berendschot TTJM, Klopping-Ketelaars IAA, et al. (2002) Macular pigment density in relation to serum and adipose tissue concentrations of lutein and serum concentrations of zeaxanthin. Am J Clin Nutr 76, 595-603.

37. Olson JA (1984) Serum levels of vitamin A and carotenoids as reflectors of nutritional status. J Natl Cancer Inst 73, 1439-1444.

38. Yeum KJ, Booth SL, Roubenoff R, et al. (1998) Plasma carotenoid concentrations are inversely correlated with fat mass in older women. J Nutr Health Aging 2, 79-83.

39. Vioque J, Weinbrenner T, Asensio L, et al. (2007) Plasma concentrations of carotenoids and vitamin $\mathrm{C}$ are better correlated with dietary intake in normal weight than overweight and obese elderly subjects. Br J Nutr 97, 977-986.

40. Kant AK (2003) Interaction of body mass index and attempt to lose weight in a national sample of US adults: association with reported food and nutrient intake, and biomarkers. Eur J Clin Nutr 57, 249-259.

41. Clevidence BA \& Bieri JG (1993) Association of carotenoids with human plasma lipoproteins. Methods Enzymol 214, 33-46.

42. Berendschot TT, Plat J, de Jong A, et al. (2009) Longterm plant stanol and sterol ester-enriched functional food consumption, serum lutein/zeaxanthin concentration and macular pigment optical density. Br J Nutr 101, $1607-1610$.

43. Neuhouser ML, Rock CL, Kristal AR, et al. (2006) Olestra is associated with slight reductions in serum carotenoids but does not markedly influence serum fat-soluble vitamin concentrations. Am J Clin Nutr 83, 624-631.

44. Connor WE, Duell PB, Kean R, et al. (2007) The prime role of HDL to transport lutein into the retina: evidence from HDL-deficient WHAM chicks having a mutant ABCA1 transporter. Invest Ophthalmol Vis Sci 48, 4226-4231.

45. Smith W, Mitchell P, Leeder SR, et al. (1998) Plasma fibrinogen levels, other cardiovascular risk factors, and age-related maculopathy - The Blue Mountains Eye Study. Arch Ophthalmol 116, 583-587.

46. Hirvela H, Luukinen H, Laara E, et al. (1996) Risk factors of age-related maculopathy in a population 70 years of age or older. Ophthalmology 103, 871-877.

47. Delcourt C, Michel F, Colvez A, et al. (2001) Associations of cardiovascular disease and its risk factors with age-related macular degeneration: the POLA study. Ophthalmic Epidemiol 8, 237-249.

48. Seddon JM, Cote J, Davis N, et al. (2003) Progression of agerelated macular degeneration: associated with body mass index, waist circumference, and waist-hip ratio. Arch Ophthalmol 121, 785-792. 